\title{
The Web of Inquiry: Computer Support for Playing Epistemic Games
}

\author{
Todd A. Shimoda and Marcela Borge
}

\begin{abstract}
We describe and evaluate the Web of Inquiry, an online environment for learning and doing science inquiry, and compare it to the framework of epistemic forms and games. Epistemic games are the constraints, entry conditions, moves, and transfers for completing epistemic forms, which are general target structures for representing knowledge. Example epistemic forms include lists, compare-and-contrast tables, systems dynamics models, and cause-and-effect analyses. Intended for teaching science for students from 10 years-old and up, the Web of Inquiry allows teachers to create templates corresponding to epistemic forms and science inquiry. Students use the Web of Inquiry to play epistemic games to complete the targeted forms. The Web of Inquiry includes workspaces, tools, reflective and standards-based assessment, and advice in the form of task, cognitive, social, and metacognitive agents. In tests in several US schools, the Web of Inquiry provided rich opportunities for students to learn and discuss epistemic forms and games in learning science, and was successful in improving students' science inquiry skills.
\end{abstract}

Index Terms-Educational technology, epistemic forms, epistemic games, inquiry learning, science education.

\section{SCIENCE LITERACY AND EDUCATION IN THE US}

The problem we are focusing on is improving science domain knowledge through the use of technology to support teaching and learning. A hurdle in developing the general public's interest in and understanding of science is that according to surveys conducted by the US National Science Foundation science literacy in the United States is fairly low [1], [2]. Scientific literacy is the knowledge, understanding, and ability to communicate scientific concepts and processes required for personal decision making, participation in civic and cultural affairs, and economic productivity, including such issues as climate change, personal health, and resource allocation.

The National Science Foundation survey also reports that the majority of the general public knows only a little about science [1]. For example, most Americans know that Earth travels around the Sun (although nearly one quarter believe the Sun revolves around the Earth) and that light travels faster than sound. However, few can successfully define "molecule." Ref. [2] also according to the survey results, most Americans are unfamiliar with the scientific process,

Manuscript received December 3, 2014; revised February 27, 2015. Support for this research is provided by US National Science Foundation Grant REC-0337753.

Todd A. Shimoda is with Pomona College, Claremont, CA, USA (e-mail: todd.shimoda@pomona.edu).

M. Borge is with Penn State University, College Station, PA, USA (e-mail: mbs15@psu.edu). including knowledge of what it means to study something scientifically, how experiments are conducted, and the use of statistical concepts such as probability. Furthermore, belief in pseudoscience such as astrology is relatively high. Pseudoscience consists of claims presented so that they appear scientific even though they lack supporting evidence and plausibility. In contrast, science is a set of methods designed to describe and interpret observed and inferred phenomena, and is aimed at building a testable body of knowledge open to rejection or confirmation.

Many students are also misinformed about what it means to be a scientist. According to Draw-a-Scientist Test research [2], the stereotypical image of a scientist (nerdy white male in a lab coat and glasses) is alive and well in the minds of children. Moreover, children seem to form this image early in life, by the time they reach the second grade. It is even more ingrained and pronounced among older children. However, more than 90 percent of survey respondents think scientists are "helping to solve challenging problems" and are "dedicated people who work for the good of humanity" [2].

People who are scientifically literate can ask, find, or determine answers to questions about everyday experiences. They are able to describe, explain, and predict natural phenomena. Scientific literacy has different degrees and forms; it expands and deepens over a lifetime, not just during the years in school. Given the lack of knowledge of scientific method and the disjoint between understanding published research, we believe science education should cover these topics as well as content knowledge.

Committees and working groups of scientists, teachers, and other educators appointed by the US National Research Council developed the National Science Education Standards [3]. They engaged in a four-year process that involved review and critique by 22 science education and scientific organizations and broad state and local participation of over 18,000 individuals, including scientists, science educators, teachers, school administrators, and parents. The guiding principles behind the NSE Standards are a) science is for all students, b) learning science is an active process, c) school science reflects traditions of contemporary science including inquiry methods, d) improving science is part of system-wide educational reform. The NSE Standards outline a broad base of knowledge and skills for a lifetime of continued development in scientific literacy for every citizen, as well as provide a foundation for those aspiring to scientific careers. Some of the recommended standards are [3]: a) Unifying Concepts and Processes (systems, order, and organization; evidence, models, and explanation; change, constancy, and measurement; evolution and equilibrium; and form and function), b) Science as Inquiry (abilities necessary to do scientific inquiry, and understandings about scientific 
inquiry), and c) Science in Personal and Social Perspectives (personal health; populations, resources, and environments; natural hazards and risks; and science and technology in society).

Though these standards are intended to support the guiding principles, the practice of science requires more than recollection and application of a collection of concepts and methods. The practice of science requires a systemic understanding of the knowledge building enterprise that is science: how differing questions necessitate specific processes for selecting, organizing, and interpreting information through the creation of knowledge artifacts. Collins and Ferguson [4] refer to this as epistemic forms and epistemic games.

\section{EPISTEMIC FORMS AND GAMES}

To help us understand what scientists do, Collins and Ferguson [4] describe the kinds of knowledge structures and processes scientist use as epistemic forms and games. Epistemic forms are visual representations or knowledge structures that provide a general framework to organize information, i.e., tables, models, taxonomies, charts, etc. Epistemic games are the specific sets of rules and strategies that can be applied to organize information within the structure. The rules and strategies include entry conditions, moves, and transfers to other games. The basic goal of each game is to finish filling out the form and create new knowledge. Learning the epistemic forms and games of a domain should increase literacy in that domain [4]-[6].

Collins and Ferguson [4] present a collection of common epistemic games and there related forms in order to help illustrate their relationship to the knowledge building process inherent of science practice. They begin by describing the most basic epistemic game, making a list. The epistemic form associated with this game is the list itself. The entry condition for the list is the answer to a question, e.g., What are the variables that affect a rolling object on a ramp? Or, what are the characteristics of an animal species?

The moves in an epistemic game denote what actions we can take with information at different points, how we move, manipulate, modify, or arrange information. Returning to Collins and Ferguson's [4] example, in the list game we can choose to add or remove an item, revise an item, combine items, split an item, or substitute an item. The list-making constraints provide guidance in making the moves of the game. For example, when adding a new item, it should be similar to other items in specificity, be distinct from other items, and be brief in scope. Collins and Ferguson [4] also state the creation of a new form as another possible move; this occurs when a player recognizes that the existing form cannot adequately organize information to answer the question that drives the game. For example, questions that require the evaluation of multiple dimensions might be better served by a table than a list.

Collins and Ferguson [4] (in playing the list game) have identified three main areas of epistemic games: structural analyses, functional analyses, and process analyses. Structural analyses determine the nature of $x$, by unpacking $\mathrm{x}$ into its parts, and describing relationships. Collins and Ferguson [4] list the following structural analyses games and example forms or applications: a) spatial decomposition (map), b) temporal decomposition, stage models (geological eras), c) compare and contrast (planet differences table), d) cost-benefit analysis (project alternatives), e) primitive-elements (periodic table), f) cross product or table (two related lists), g) tree structure, hierarchy (biological taxonomy), and h) axiom systems (Euclidian geometry).

Functional analysis games determine the causal or functional structures that relate elements in a system. Examples include: a) critical-event analysis (engineering failures), b) cause-and-effect (models of events), c) problem-centered analysis (human computer interaction), d) multi causal analysis (and/or graphs), and e) form-and-function analysis (physical systems).

Process analysis games model dynamic phenomena. Examples include: a) systems-dynamics models (feedback loops), b) aggregate-behavior models (molecular interactions), c) constraint systems (controlling variables), d) situation-action models (intentionality in social sciences), and e) trend analysis (cyclical variations)

Pertinent to our development of teaching and learning environments, Collins and Ferguson [4] propose that epistemic forms and games be taught as explicitly as other factors of science such as concepts, laws, theories, and methods. They also state that the interrelation and use of epistemic forms and games in the complex inquiry done in the real world of science has yet to be studied in depth. They call for other researchers to identify other epistemic forms and games, as well as create more detailed theory about them.

\section{THE WEB OF INQUIRY ENVIRONMENT}

To further develop the theory of epistemic forms and games, especially in developing knowledge about scientific inquiry and teaching it to students, our research group (Thinker Tools, www.thinkertools.org) has created and tested inquiry-based curricula and educational technology [7]-[10]. This previous research has shown that merely having students follow step-by-step experiments does not necessarily contribute to a deep understanding of the target knowledge nor increase the transferability of the knowledge to new situations. Our model of teaching science is through reflective inquiry using constructionist principles [6], [10], [11], which emphasize learners actively building new knowledge on their existing knowledge. The constructionist principles we use in developing computer support account for learner control of the environment, individual learning differences, and includes workspaces for projects, assessment and self-reflection opportunities, general and scaffold (tailored, flexible, and temporary) advice, and tools to support inquiry, communication, and the creation of inquiry artifacts such as lists, tables, graphs, and reports.

The model of scientific inquiry that has evolved out of our research is a cyclical series of interrelated steps (Fig. 1). The six steps we define are a) Question and Theorize (describe the research topic of interest and specify the research question), b) Hypothesize (develop alternative explanations of some phenomenon), c) Investigate (test the hypotheses), d) Analyze (summarize and find patterns in the data), e) Synthesize (form 
a current best theory to explain the data), and f) Extend (describe uses of the theory, limitations, and future research). The process is cyclical because the results of one study will lead to another research question. We are not claiming that this is the only true representation of inquiry; there are in fact many different kinds. However, our model has proved to fit many kinds of research, and is one for which we have developed and tested curricular support for teachers and students.

\begin{tabular}{|c|c|c|c|}
\hline \multicolumn{4}{|c|}{$\begin{array}{c}\text { Web of Inquiry } \\
\text { Support for inquiry tasks, cognitive and social skills, and metacognition } \\
\text { Templates }\end{array}$} \\
\hline \multicolumn{2}{|l|}{$\begin{array}{l}\text { Target form } \\
\text { Entry conditions } \\
\text { Constraints } \\
\text { Moves } \\
\text { Transfers }\end{array}$} & \multicolumn{2}{|l|}{$\begin{array}{l}\text { Learner control } \\
\text { Advice and tools } \\
\text { Individual differenc } \\
\text { Tasks and projects }\end{array}$} \\
\hline \multicolumn{2}{|c|}{ Template example } & Advice & Assessment \\
\hline Target form & List of variables & \multirow{4}{*}{$\begin{array}{l}\text { Concepts (variable, } \\
\text { phenomenon, research } \\
\text { questions) } \\
\text { Criteria (for choosing } \\
\text { variables) } \\
\text { Questions to ask (which } \\
\text { variables can be changed?) } \\
\text { Examples (from various } \\
\text { sciences) }\end{array}$} & \multirow{4}{*}{$\begin{array}{l}\text { Did you think of as many variables as you } \\
\text { could? } \\
1 \text { - We came up with a few obvious variables. } \\
2 \text { - We have several variables built on initial } \\
\text { ideas. } \\
3 \text { - We have a thorough list of variables all } \\
\text { related to our topic. }\end{array}$} \\
\hline Entry conditions & Research question formation & & \\
\hline Constraints & $\begin{array}{l}\text { Must affect phenomenon or be affected by } \\
\text { phenomenon }\end{array}$ & & \\
\hline Moves & $\begin{array}{l}\text { List variables that can be changed or might be } \\
\text { affected by the change }\end{array}$ & & \\
\hline Transfers & $\begin{array}{l}\text { Hierarchical or differentiated lists (1) Things } \\
\text { you will change or manipulate; (2) Things you } \\
\text { will keep the same; and (3) Things you will } \\
\text { observe or measure that might be affected } \\
\text { during your investigation. }\end{array}$ & $\begin{array}{l}\text { Pick variables that should have } \\
\text { the most effect. Control other } \\
\text { variables that might have an } \\
\text { effect. Think about the kind of } \\
\text { data that people would believe. }\end{array}$ & $\begin{array}{l}\text { Have you thought of one or more variables to } \\
\text { measure the outcomes or effects you are } \\
\text { planning to study? }\end{array}$ \\
\hline
\end{tabular}

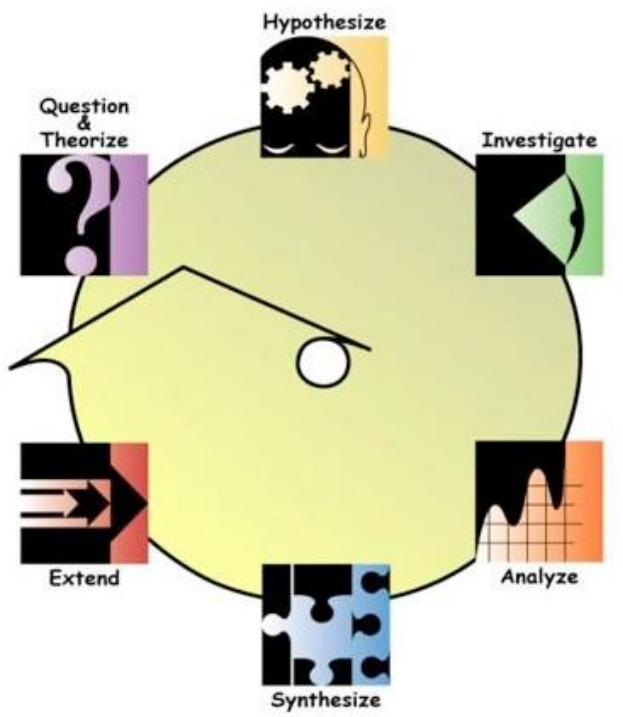

Fig. 1. The inquiry cycle.

The current iteration of our inquiry teaching and learning environment is the web-based Web of Inquiry (WOI, www.webofinquiry.org).Built primarily using ColdFusion and a SQL Server database, the main features of the environment related to our model of inquiry include project templates, workspaces, support tools, built-in assessment, and inquiry, social, and meta cognitive advice. We next describe these features and how they apply to epistemic forms and games. Table I is a summary of the WOI features, main design parameters, and relation to epistemic forms and games.

\section{A. Modifiable Project Templates}

A WOI project template provides the tasks and subtasks students should complete in their inquiry projects. Teachers can use a template editor tool in the WOI to build a project template. The template editor not only helps teachers create the tasks but also allows them to attach specific advice to a task by linking to the built-in WOI advice. Student self-reflection and teacher assessment can also be assigned to a task in the template editor. While our Inquiry Cycle model is supported in the WOI through an established template, the template editor can modify our template, or create a completely different one.

A project template corresponds to an epistemic game template. A template could be created for structural, functional, or process analyses. Our template can be seen as a series of nested epistemic games and forms. The top level epistemic game is called the Inquiry Cycle, with the ultimate target structure being the development of a model that explains a phenomenon and leads to a new research question. This parent template includes within it other epistemic games such as the research question game, the hypotheses generation game, the hypotheses testing game, the data analysis game, and the theory synthesizing and extending game. Within each of those games there are specific epistemic forms to complete.

For example, in the research question game, students are asked to create a list of variables ("things that might affect the phenomenon that you are going to study. Include variables you can change and variables that might be affected by those changes. Also include variables that might have an effect."). Another epistemic form the students are asked to complete is a process model for their theory ("Suggest a mechanism or process that explains why the things predicted by your theory happen. You may want to include a model or diagram to make 


\section{it clear.")}

We should emphasize that these templates can also be seen as forms to complete in epistemic games. Our templates provide guiding structures to help young students select, organize, and interpret their work and the knowledge they create. However, the templates only provide minimal structural support and not the step-by-step instructions for science practice that has become so common in $\mathrm{K}-12$ education. Rather than tell students what to do at each step, we use additional features to push students to question their own epistemic game play and the validity and accuracy of the forms they create. We distribute knowledge within the project workspace through a collection of advisors and tools that can help students understand, critique, and improve their ability to play the game of science.

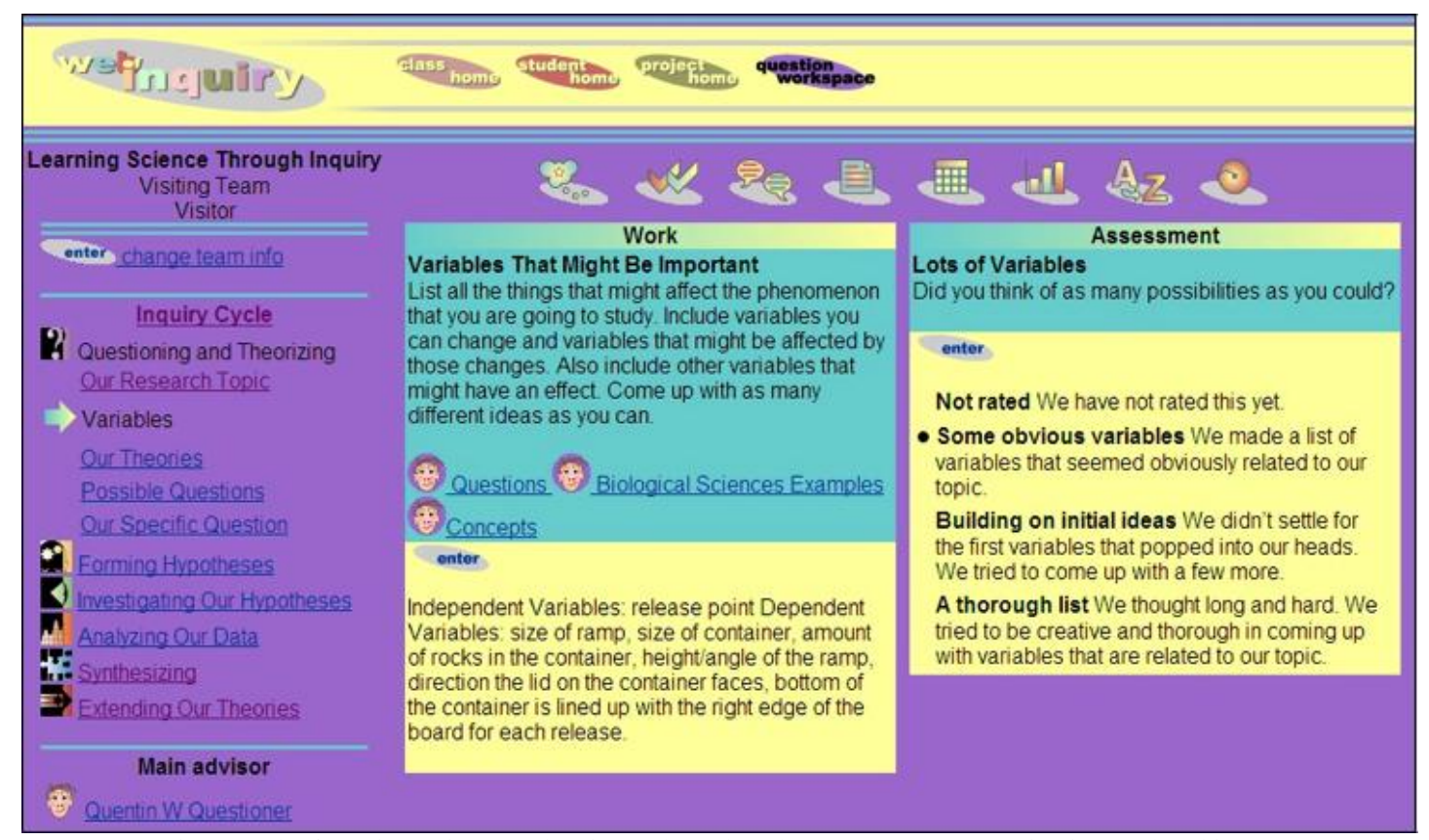

Fig. 2. Web of Inquiry main page showing task work and assessment areas, navigation, and tool icons.

\section{B. Project Workspace and Tools}

When a project template is completed and the teacher gives access to their class, the students individually, or more usually in small teams, work on their projects. The project workspace (Fig. 2 and Fig. 3) provides a text box where students record their work related to a task. The task instructions from the template are shown above the text box, as well as any advice links that were entered in the template for that task. In the workspace, the students can also link to images, video, sound, and other external documents they have created. The navigation to the tasks and subtasks is provided on the left side of the text box.

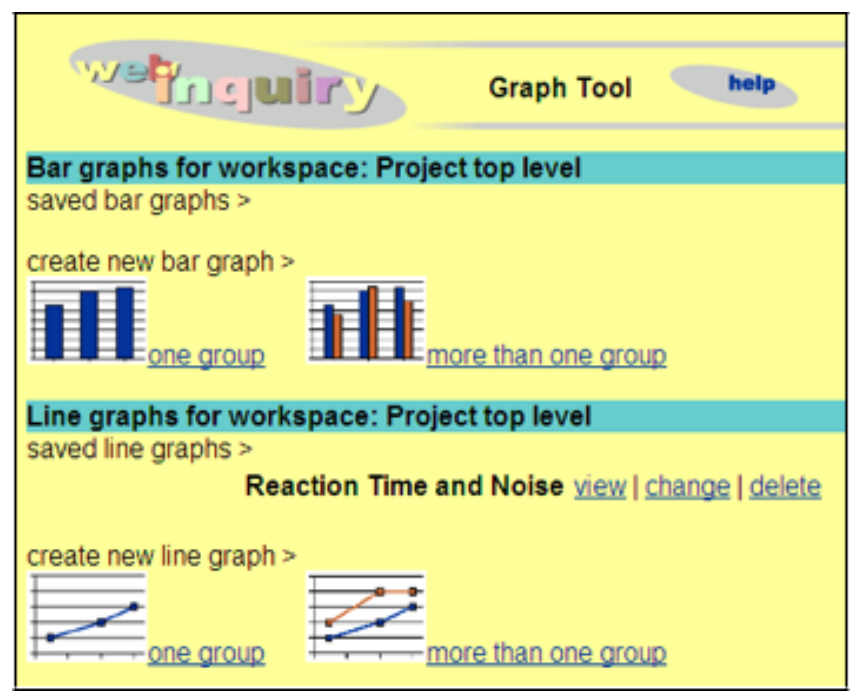

Fig. 3. Graph tool.
Above the task work space is a row of icons that launch tools which support the students as they work on their projects. There are three main categories of tools: Task, Cognitive and Met cognitive, and Social. The Task category includes the Project Progress Tool (tracks the students' progress in completing tasks), the Report Builder (builds a printable report of a project), Data Entry and Table Tool (creates variables, data, and tables), and Graph Builder (creates graphs from entered data). The Cognitive and Meta cognitive category includes the Thinker Tool (provides a place for notes and thoughts for a student or team only), the Dictionary (a glossary of concepts), and the Advice Search Tool (allows all advice to be searched by keyword.) The Social category consists of the Discussion Tool, which allows threaded discussions between any student and team in the class as well as with the teacher.

In terms of epistemic forms and games, the task template instructions and workspace provide a place for students to play their epistemic game to complete the target epistemic form. This provides the entry condition for playing a particular game. In the research question game example, one of the subtasks is to create a list of variables that might affect the phenomenon the students are going to study and help answer their research question. The students can enter their list in the workspace directly, use the Data and Table Tool to enter them in a single column table, or provide a link to a document that contains the list. The constraints for the variable list form are also provided: Variables must affect phenomenon or be affected by phenomenon. The moves allowed include add, delete, or edit variables that can be 
changed to test a theory. A transfer allowed in another subtask suggests the students modify their list into a hierarchical or differentiated list of 1) variables that students will change or manipulate, 2) variables they will keep the same; and 3) variables they will observe or measure that might be affected during your investigation.

In addition to the Data and Table Tool, the other tools also support students as they play the epistemic game. For example, the Dictionary provides definitions for such terms as "variable" and "phenomenon," the Advice Search tool allows students to find advice for completing a list, and the Discussion Tool provides students a place to get feedback on their list and offer suggestions for others.

\section{Inquiry Advisors}

The WOI includes advice in the form of advisors. Task advisors are based on our Inquiry Cycle (e.g. Quentin Questioner), cognitive advisors (e.g., Ingrid Inventor), social advisors (e.g., Keiko Collaborator), metacognitive advisors (e.g., Ricky Reflector), and system development advisors (e.g., Imogene Improver). Advisors talk about the goals that need to be pursued to complete a task or improve a skill, why one should pursue them, and examples of what work that meets those goals looks like. The agents also provide strategic advice for how to achieve each goal. The community of advisors, working together, portrays inquiry as a distributed process in which various capabilities, like analysis and synthesis, come into play to support the students complete their projects. We personify the cognitive models of each of these processes in the form of advisors like Ann Li Analyzer or Sydney Synthesizer, so that the advisors can be thought of as roles the students may take, or different hats to wear, at different times in their research. The idea is that students will learn to switch in and out of these different hats or roles as they engage in the complex process of scientific inquiry.

An example of the kinds of resources advisors give is shown in Fig. 4. Sydney Synthesizer can talk about ways for students to think in creating their current best theory to account for their research findings. There are similar advisors for all of the inquiry tasks. In addition to explaining goals and purposes to students, the advisors provide strategic advice for how to achieve each goal. This strategic advice can take the form of strategies to try, questions to ask yourselves, and things to say (there are sentence starters to get them going). Through this type of advice, particularly the strategies they can try, we hope to enable students to acquire widely-useful cognitive strategies, like brainstorming or using visual representations, for achieving their goals.

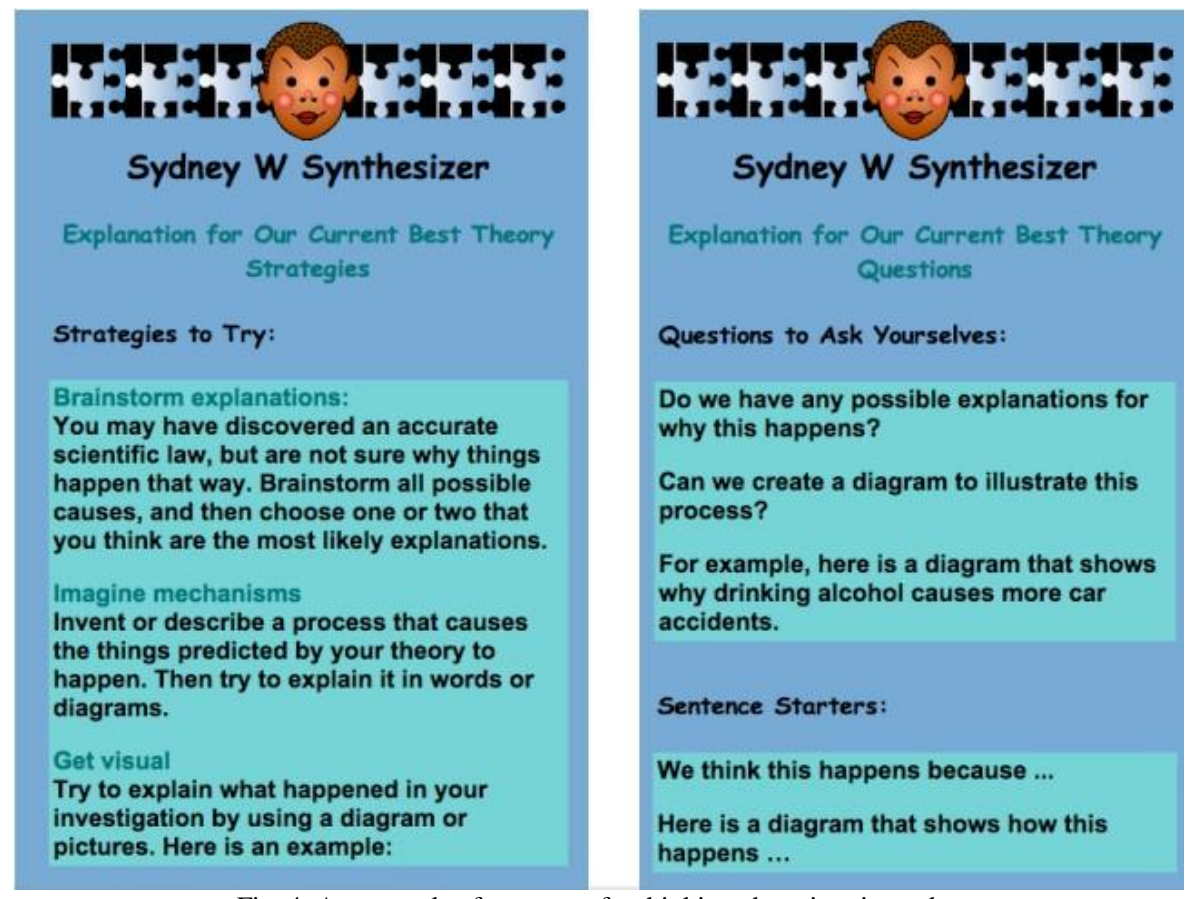

Fig. 4. An example of resources for thinking about inquiry tasks.

To support the playing of epistemic games, advisors provide advice to help students understand the target form, entry conditions, constraints, and moves. For example, in the variable list game, the advisors' advice includes concepts (variable, phenomenon, research questions), criteria (for choosing variables), questions to ask (which variables can be changed?), and examples from various sciences.

In helping students make transfers to other games, for example, to differentiated lists, advisors offer advice in completing the new target form from the existing list. In this case such advice includes concept definitions for dependent and independent variables. Strategies are given for making differentiations between variables types, and motives for making such differentiations. Goals for making the differentiated lists are also provided.

\section{Assessment Workspace and Project Scoring}

The assessment work space contains self-assessment items addressing the goals for each task and subtask, which are displayed to the right of the workspace. Examples of Goal Assessments are shown in Fig. 5 for the task of students constructing their Current Best Theory. Students use the goal assessments to record the current state of their progress, and the level descriptions give them ideas for what to aim for next 
to improve their work pertaining to that goal. If the students have previously made an assessment, that choice is marked. They can change their previous assessment if they choose to reflect their progress for that goal.

Assessment
Seems Convincing
Do your current best theory's descriptions,
predictions, and explanations seem believable
and fit with everything else you know about your
research topic?
enter
Not Plausible This theory doesn't seem
believable. It doesn't fit with some things we
know about the topic.
- Fairly plausible This theory seems pretty
believable, and it's consistent with most of the
things we know about the topic.
Highly plausible This theory seems very
believable and is consistent with what is
known about this topic.

Fig. 5. Goal assessment for current best theory.

Teachers and researchers score projects by accessing students' projects through a "project scoring" link found on the teacher and researcher homepages. Scoring is accomplished through an assessment tool that displays all types of assessment items, including standards, goals, and analytic questions. Assessment items are not necessarily the same for teachers and students. For instance, students use only the goal assessments associated with each inquiry subtask while they do their work, while teachers and other raters answer additional, analytic questions in addition to making goal assessments while they are reading through the students' projects. And attend of this process, they make proficiency judgments for each of the science inquiry standards.

Similarly, the WOI assessment feature supports playing epistemic games to complete the target epistemic form. For an example, in the variables list game, the assessments prompt students to evaluate the quality and quantity of their list in satisfying the constraints and moves in that game. Specifically, an example of the assessment is: "Did you think of as many variables as you could? 1 - We came up with a few obvious variables. 2 - We have several variables built on initial ideas. 3 - We have a thorough list of variables all related to our topic." Another example of this self assessment question in the variables epistemic game is: "Have you thought of one or more variables to measure the outcomes or effects you are planning to study? 1 - Not sure, we have only a vague idea for how to measure the outcomes we will be studying. 2 - Possible measures, we've developed some possible ways for measuring the outcomes we will be studying. 3 - Clear measures, we have developed some clear ways to measure the outcomes, which other scientists will accept as objective and valid."

\section{Classroom Usage AND PREVIOUS Tests OF THE WOI}

For evaluation purposes, the WOI was implemented in fifth through seventh grade classrooms (age 11-13) in seven US schools in California and Washington State [7], [12]. The schools represented a range of urban public to suburban populations. Teachers developed the project-based inquiry units for the subjects they were teaching, and were trained in using the WOI to support their teaching and the students' work. Teachers were provided with a sample to illustrate how such a unit might be organized, how the environment is used to support the students as they worked, and how to implement the built-in assessments.

The main tasks a teacher needed to accomplish for teaching a single inquiry project using the WOI included: a) determining the scientific and inquiry content of the project to fit their curriculum, b) using web tools to set up a class and project, if one has not already been established, c) using web tools to enroll their students in the class project and to create project teams (the students can do this themselves), d) introducing the class to the WOI website and establishing timelines for their projects, e) monitoring instruction and conducting discussions, and f) assessing students' projects.

Content areas and specific projects in the content areas the teachers used in their classes include those shown in Table II

TABLE II: SCIENCE CONTENT AND REPRESENTATIVE PROJECT TITLES

\begin{tabular}{|l|l|}
\hline \multicolumn{1}{|c|}{ Content Area } & \multicolumn{1}{|c|}{ Representative Project Titles } \\
\hline $\begin{array}{l}\text { Earth and Ecological } \\
\text { Science }\end{array}$ & Stream Tables (erosion and landforms) \\
\hline $\begin{array}{l}\text { Physical and Materials } \\
\text { Science }\end{array}$ & $\begin{array}{l}\text { Sinking and Floating (buoyancy) } \\
\text { Pulleys (work energy) } \\
\text { Solar Ovens (light radiation and heat) }\end{array}$ \\
\hline Biology & Plant Reaction to Light (phototropism) \\
\hline Behavioral Science & $\begin{array}{l}\text { Music and Math (cognition and attention) } \\
\text { Color and Human } \\
\text { Behavior(affect and visual } \\
\text { sense) } \\
\text { Reaction Times (cognitive distraction) }\end{array}$ \\
\hline Health and Nutrition & Effects of Nutrition on Studying \\
\hline
\end{tabular}

The students used the WOI to develop competing theories about a phenomenon assigned to a class, then designed and carried out experiments to see which of their models had the most empirical support. As they did their research, students completed self- and peer-assessment practices to monitor their work and get feedback on how to improve their research projects.

We have previously evaluated the WOI in order to test its utility as a support for the practice of science and facilitator of scientific discourse [7]. Specifically, we asked: a) did use of the system help students to improve their understanding and application of theory building epistemic forms and games? and b) did the system aid in facilitating student-teacher discourse and in supplementing collaborative inquiry learning?

To answer the first research question, students inquiry knowledge was tested using the Inquiry Test [13] which was developed in the Thinker Tools research group to evaluate the inquiry concepts represented in the Inquiry Cycle, as well as other skills involved in doing inquiry. For example, a student's hypotheses would be evaluated on dimensions of clarity, alternatives, variables, reasoning, and ability to answer the research question. Students are presented a topic and are asked to complete a "thought experiment" similar to this: "Shandice, a middle school student, drew a map that showed all the detentions reported to the principal last week. 
She wants to know why there are more in classroom 3 . What advice would you give her to help her answer her question?"

Pretests and posttests were givento88 students who completed projects using the WOI [7], [13]. The results showed a significant improvement in total inquiry scores, $F$ $(1,87)=6.6, p<.006$. Most of the individual inquiry concepts and skills also showed significant improvement including: hypothesis, investigate, model, science understanding, reasoning carefully, and inventiveness. Two areas that did not show significant improvement were analyze and evaluate, which were also the lowest scoring areas for students overall.

In addition to the inquiry skills pretest and posttests, a set of the students' projects were scored using the science standards assessment items built into the WOI [13]. Teachers were trained in using the assessments, and the scoring was blind (students were not identified). The items were scored on a scale of 1 to 4 , where $1=$ below basic, 2 = basic, 3 = proficient, and $4=$ advanced. The mean total score was $2.01(S D=.68)$. Table III reports the complete results [13].

TABLE III: WOI PROJECT SCORING

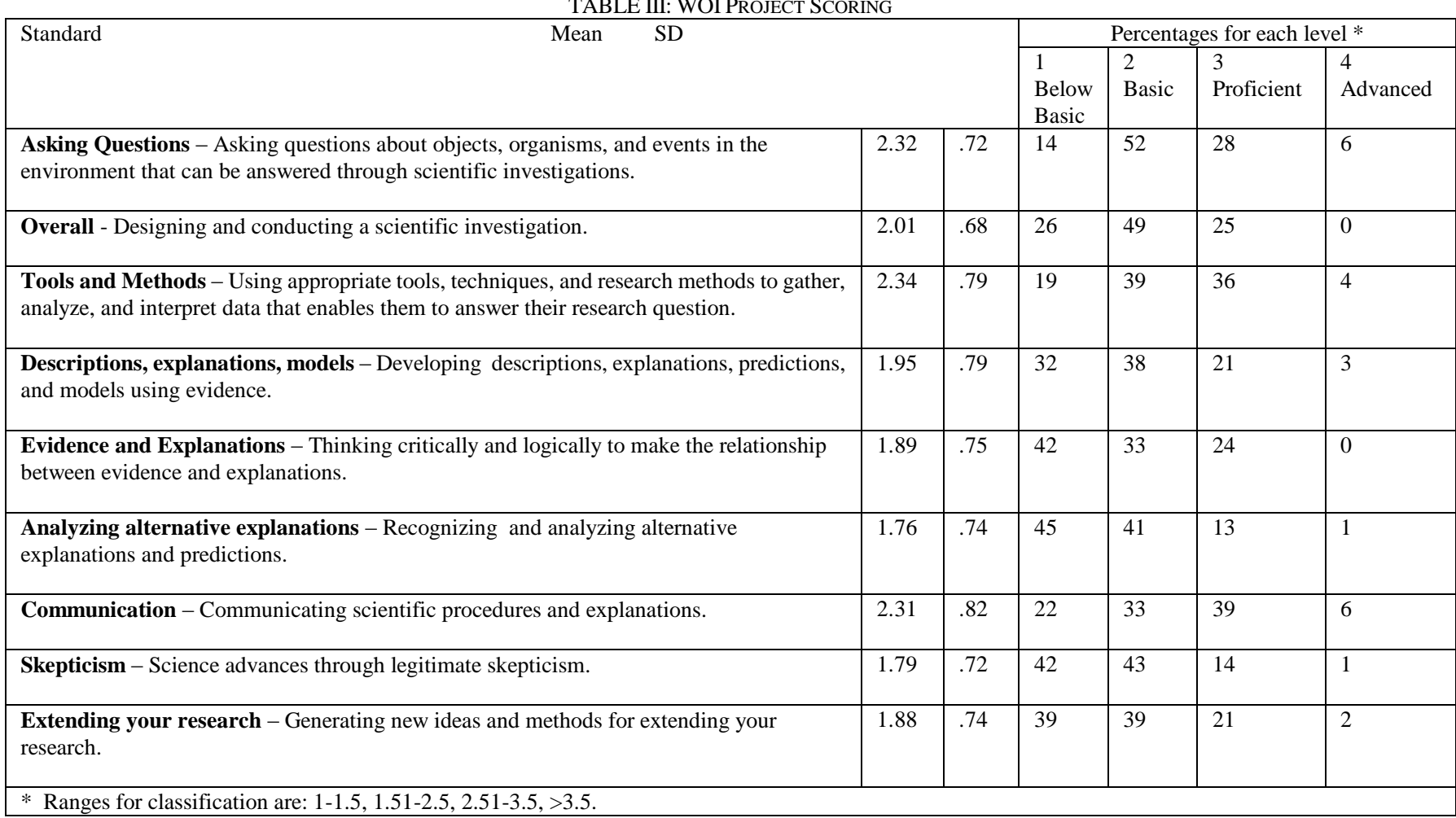

We also reported on the analysis of transcripts of student-to-student and teacher-student interactions to show how students demonstrate their use of the WOI in conversations [7]. They clearly depended on the system to guide them along on their thought process. For example, a student asks what to do next, and another student looks at the system and states that they now have to explain their theory and discuss the precise language to explain their findings. The students were building on each other's ideas and have already developed theory, but require use of the system to remember what they wrote. Other transcripts show that having feedback prompts the students to verify or reflect on their own understanding of the relationship between key inquiry concepts, including their analysis of the quality of the feedback. The extent to which students develop these abilities is facilitated by the WOI and is shown to be important in developing epistemic understanding [14], [15].

The following is an example of students evaluating the quality of the theory and hypotheses section of another group's solar oven project. The turns are numbered for ease of reference:

1) $S 1:$ (Begins to read aloud from the other team's WOI report) 'We're going to make a change to our oven and try to make it hotter...' OK - for their theories they said that the temperature had changed but they didn't really say why, so...(begins to type) Why do you think that the temperature in your oven will change-

2) $S$ 2: Get hotter...

3) S 1: Get hotter when you make the change to your oven? Do you have a reason?

4) S 2: Yeah, they said it will just get hotter but they didn't put a reason.

5) $\quad$ 1: A theory, you pretty much have to have a reason to back it up. And they just said that it will probably get hotter, they didn't say why.

6) S 2: (Types) Good hypotheses, but what are your reasons for these?

7) S 1: To make a hypothesis, like a guess, you probably have to have like a reason why you think it's gonna happen. Because...

8) S 2: Yeah, or else you can't support it at all.

9) $S$ 1: You could just be saying, 'this happened but I don't know why.'

10) $S$ 2: Like, so why did you choose it? We don't know.

The students demonstrate the extent to which they have internalized important thinking processes associated with theory building as they discuss the progress and quality of the other group's epistemic game playing. For example, they 
point out an important constraint: theories and hypotheses must have reasoning behind them (turns 5-8). They also suggest that the next move in the game is to provide the reasoning behind the theory and hypotheses so they can be fully evaluated (turns 1, 6, and 8).

\section{CONCLUSIONS}

There is a divide between what science practice is and what students are taught to do in science classrooms. Though the practice of science is a systemic knowledge building process this is largely not what students experience in most science classrooms. Students rarely get make the types of decisions that would lead to the development of a systemic understanding of the relationship between epistemic games and epistemic forms. Students' reflective practices, as they play the game of science and work to create knowledge artifacts, is also largely unsupported.

Technology can provide many different types of support, but too much support can hinder learning: how will students ever learn to select epistemic processes and forms to guide their lines of inquiry if the technology is always making those decisions for them? In our haste to ensure that students demonstrate knowledge retention by passing tests, we have lost sight of the importance of science exploration as tool for learning and engagement.

Rather than using technology to rigidly constrain student activity, our group chose to create target structures to support students' exploration of science practice. We then complemented these structures with features to articulate the entry conditions, moves, strategies, and target forms inherent of the epistemic game that is science practice. Such an approach can help students to develop a richer understanding and appreciation for science while simultaneously improving students' ability to understand and regulate their own thinking processes [7], [10]. Teachers were able to engage students completing their inquiry-based projects and the assessments that are linked to US National Science Standards such as those for science inquiry to improving classroom teaching and the learning of science. The use in real classrooms showed how a constructivist approach to developing students' inquiry abilities can lead to a richer understanding of science practice.

We have also shown that the WOI has several aspects that correspond to Collins and Ferguson's concept of epistemic forms and games [4]. For example, coming up with a research question involves playing the list game to create a list of possible variables. Developing and testing hypotheses involves differentiating those lists into independent and dependent lists. In addition to using the Web of Inquiry to complete projects, we can say that students in science classrooms using the WOI were able to play a complex epistemic game called theory building, which consists of several nested epistemic forms and games.

We intended to carefully craft and insure consistency in the language of goals, motives, and strategies across the WOI to support processes of instruction, investigation, and assessment. Having such ways of talking about practice allows members of the classroom community to share their thinking and supports individual students' metacognitive processes in monitoring, reflecting, and revising their goals and strategies as they work. Developing such metacognitive capabilities for self-regulation should help students improve the quality of the epistemic games they play and the forms they create.

The future of the Web of Inquiry includes improving support for areas students found more difficult, such as analyzing data and evaluating their data in arriving at a theory. The advice will also be more fluid and interactive based on students' responses to self-assessment and eventually using artificial intelligence for real-time analysis of their epistemic game playing. Other modifications include a user interface redesign and changes for older students. We will also be developing and testing other epistemic forms and games in other domains such as design that allow for differing types of inquiry. Another goal is to modify the WOI for use in those domains, rather than just in educational settings. To upgrade the environment to the current standard of participatory web design, we anticipate incorporating social media and open system design and platforms.

Even more broadly, further developing the WOI is itself an epistemic game, one in which we will need to deeply analyze the relation of epistemic forms and games to real scientific practices [7]-[10], [12], [13]. In playing this epistemic game we hope to develop a model of inquiry and the design technological environments that moves beyond content learning to help students develop thinking practices that live on outside of the system to be used in everyday science evaluations and explorations.

\section{ACKNOWLEDGMENT}

We thank the following for their invaluable contributions to the Web of Inquiry and this paper: Barbara White, John Frederiksen, Leslie Herrenkohl, Tammy Tasker, Min Li, Tatiana Frederiksen, Allan Collins, Suzy Loper, LeslieStenger, Phelana Pang, Eric Eslinger, and Linda Shimoda.

\section{REFERENCES}

[1] US National Science Foundation, Science and Engineering Indicators, 2014.

[2] US National Science Foundation, Science and Engineering Indicators, 2002.

[3] US National Research Council, A Framework for K-12 Science Education: Practices, Crosscutting Concepts, and Core Ideas, Committee on a Conceptual Framework for New K-12 Science Education Standards. Board on Science Education, Division of Behavioral and Social Sciences and Education, Washington, DC: The National Academies Press, 2011.

[4] A. Collins and W. Ferguson, "Epistemic forms and epistemic games: Structures and strategies to guide inquiry," Educational Psychologist, vol. 28 , no. 1 , pp. $25-42,1993$

[5] L. Sherry and M. Trigg, "Epistemic forms and epistemic games," Educational Technology, vol. 36, no. 3, pp. 38-44, 1996.

[6] D. Morrison and A. Collins, "Epistemic fluency and constructivist learning environments," Educational Technology, vol. 35, pp. 39-45, 1995.

[7] T. A. Shimoda et al., "Designing for science learning and collaborative discourse," IDC '13 Interaction Design and Children, New York: ACM, 2013.

[8] T. A. Shimoda, B. Y. White, and J. R. Frederiksen, "Student goal orientation in learning inquiry skills with modifiable software advisors," Science Education, vol. 86, pp. 244-263, 2002. 
[9] E. Eslinger, B. White, and J. Frederiksen, "A modifiable multi-agent system for supporting inquiry learning," in J. Moore, C. Redfield, and W. L. Johnson, Eds., Artificial Intelligence in Education, Amsterdam, Netherlands: IOS Press, 2001.

[10] B. White and J. Frederiksen, "Inquiry, modeling, and metacognition: Making science accessible to all students," Cognition and Instruction, vol. 16, no. 1, pp. 3-118, 1998.

[11] S. Papert and I. Harel, Constructionism, Bristol, UK: Ablex Publishing Corporation, 1991.

[12] J. Frederiksen and B. White, Classroom Formative Assessment: Investigating Models for Evaluating the Learning of Scientific Inquiry, 2005.

[13] J. R. Frederiksen and B. Y. White, "Designing assessments for instruction and accountability: An application of validity theory to assessing scientific inquiry," in M. Wilson, (Ed.), Towards Coherence Between Classroom Assessment and Accountability. The 103rd Yearbook of the National Society for the Study of Education, Part II, Chicago: National Society for the Study of Education, pp. 74-104, 2004.

[14] M. Windschitl, J. Thompson, and M. Braaten, "How novice science teachers appropriate epistemic discourses around model-based inquiry for use in classrooms," Cognition and Instruction, vol. 26, no. 3, pp. 310-378, 2008.

[15] K. O'Connor, "Communicative practice, cultural production, and situated learning: Constructing and contesting identities of expertise in a heterogeneous learning context," in S. Wortham and B. Rymes, (Eds.), The Linguistic Anthropology of Education, Westport, CT: Praeger, pp. 61-91, 2003.

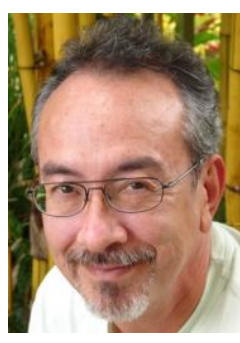

Todd A. Shimoda is a Ph.D. He is an academic applications manager at Pomona College, Claremont, California, USA. His doctorate from the University of California-Berkeley (1999) was in science and mathematics education with an emphasis in cognitive science and educational technology. His other degrees were in civil engineering and technical communication (Colorado State University, Fort Collins, Colorado, USA). His main publications include articles in Science Education, the Journal of
Experimental Education, and Environmental Psychology. He has numerous conference proceedings, book chapters, and presentations. Also as a fiction writer, he has published five novels.

Todd Shimoda's employment includes an assistant professorship at Colorado State University, and a visiting professorship at University of California-Berkeley, where he developed the Web of Inquiry. He is a consultant on the US National Science Foundation grant titled Collaborative Research: Fostering Ecologies of Online Learners through Technology Augmented Human Facilitation (CREATE, Marcela Borge P.I.) He is also Vice President of Chin Music Press (Seattle, Washington, USA).

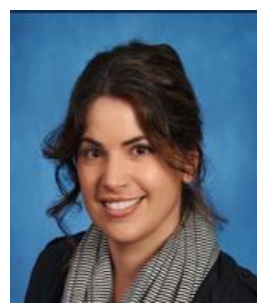

Marcela Borge is a Ph.D. She is an assistant professor in learning, design, and technology at Pennsylvania State. She received her Ph.D. from UC Berkeley in education in math, science, and technology. Borge's research interests are in the intersection of learning, self-regulation, and design. Her current research focuses on the design and assessment of cognitive tools to support collective cognitive processes at different levels of scale. Marcela Borge has also worked as part of two research groups, Thinker Tools and the Computer Supported Collaboration and Learning Lab (the CSCL group). As part of Thinker Tools group, she worked on various K-12 educational software development projects centering on inquiry science and the use of modifiable intelligent agents as a means to develop metacognitive abilities and content knowledge. As part of the CSCL group she helped to design and test systems to enhance group cognition and facilitate learning of complex phenomenon. Her latest project, funded by NSF, is called CREATE. CREATE is an interactive chat environment that helps online students develop collaborative skills through the use of embedded intelligent agents and awareness features. 